\title{
Safety belt abdominal trauma associated with anthropometric characteristics of an injured person-a case report
}

\author{
Pavel Timonov ${ }^{1 *}$, Methodi Goshev², llinka Brainova-Michich², Alexandar Alexandrov², Dimitar Nikolov²
} and Antoaneta Fasova ${ }^{3}$

\begin{abstract}
Background: The aim of this report is to present a case of a blunt abdominal trauma with vascular and spinal involvements of an overweight man, caused by the front seat safety belt.

Case presentation: It took place as a result of the car bonnet collision with a roadside pillar. During the primary inspection of the crash site, it was found that the car had collided with a roadside pillar. The driver was found dead in the driver's seat with the seat belt on. The lower part of the belt was in the inguinal region and the upper part was high on the chest, separated by the bulky midriff. The autopsy revealed a transverse fracture of the body of tenth thoracic vertebra, complicated by a torn abdominal aorta, and severe bleeding into the abdominal cavity, which was the cause of the death. The complications of the abdominal trauma result from the atypical position of the seat belt holding the upper and lower part of the body to the seat at two very distant levels, while between them the bulky, heavy midriff continued to move forward, carrying with it the vertebral column and surrounding anatomical structures. On the other hand, the forceful contact between the abdominal wall and the instrumental panel of the car generates pressure which transmits force through the adjacent organs to the aortic wall. The specific anthropometric features of the victim had an impact on the mechanism of death. The improper position of the seat belt relative to the body affected the severity of abdominal injuries, instead of protecting from them.

Conclusions: The driver's body disproportion, combined with the restraining effect of the seat belt, could increase the risk of a fatal outcome. It is incorrect to think that if the victim had not worn a seat belt, he would have survived. The safest seatbelt type for occupants with a similar anthropometric data would be the 4-point seat belt system, which is used in children's car seats. This type of safety belt is crossed over the chest and abdomen and holds the entire trunk better at dynamic loads in all directions.
\end{abstract}

Keywords: Safety belt trauma, Chance fracture, Abdominal aorta, Spinal fracture

\section{Background}

Blunt abdominal trauma with major vascular involvement is found to be rare (Freni et al. 2013). Blunt abdominal aortic injury is a rare entity. Michaels et al. (1996) reported only 7 patients with abdominal aortic injury after blunt force in 5676 patients admitted with trauma. In contrast, the closed chest trauma involving ruptures of thoracic organs and vessels causes $20-40 \%$ of motor vehicle fatalities

\footnotetext{
* Correspondence: pavelttimonov@yahoo.fr

'Department of Forensic Medicine and Deontology, Medical

University-Plovdiv, Bulgaria, 15a Vassil Aprilov Blv., 4000 Plovdiv, Bulgaria

Full list of author information is available at the end of the article
}

and the thoracic aorta is ruptured in $10-20 \%$ of the fatalities (Greendyke 1966; Frey 1970; Sutorius et al. 1973; Hossack 1974; Sevitt 1977a, 1977b; Gotzen et al. 1980; Newman and Rastogi 1984; Brundage et al. 1998; Burkhart et al. 2001; Richens et al. 2003; Fitzharris et al. 2004; Schulman et al. 2007; Bertrand et al. 2008). Aortic trauma is also an important cause of death within $1 \mathrm{~h}$ of the impact injury (Primm et al. 1979; Wilson and Hutchins 1982). Greendyke (1966) and Sevitt (1977a, 1977b) found that a transverse tear of the descending aorta at the isthmus distal to the left subclavian artery was the primary site of aortic laceration. The location is near 
the distal aspect of the aortic arch and represents a transition from a relatively mobile arch to a tethered descending portion with posterior intercostal arteries that lead off posterolaterally (Viano 2011). It is this narrowed portion of the aorta where the ligamentum arteriosum is attached. Katyal et al. (1997) showed that $94 \%$ of aortic ruptures involved the isthmus. The types and directions of mechanical forces cause variable patterns of injury; thus, the onset of symptoms can be different. The associated abdominal viscus and/or vertebral lesions must always be taken into account (Freni et al. 2013). Therefore, the confirmation of the accurate diagnosis and further complications is necessary to administer the adequate surgical treatment.

The types of lab belt abdominal aortic trauma include a severe blow to the abdomen, a crash injury, or a transverse shear injury produced by a seat belt during a sudden anterior deceleration (McEwen et al. 1999). The presumed mechanism of the abdominal aortic injury is the combination between the direct and indirect forces, mentioned above. In the case of vehicular accidents, the external force is commonly the rim of a steering wheel or the lap-strap of a seat belt (Sampsell 1967). The presence of a seat-belt sign is the evidence for an external force. In addition, bruising to the trunk and abdomen in a seat belt position is an obvious sign that suggests an increased risk of abdominal and thoracic injury (Masudi et al. 2017). Our case report confirms the occurrence of spinal cord trauma and aortic disruption as associated injuries.

A key element to ensure the safety of occupants in the car cabin is the safety belt. If the car suddenly stops or sharply reduces its speed, the driver and passengers continue their movement with the same speed and in the same direction. Thus, they are at risk of strikes in various objects in the automotive interior space or from falling out of the car. Therefore, retention of travelers to the seats is important for their safety. Seat belts operate just as a constraining factor (Ichikawa et al. 2002; Nagy et al. 2000).

All experimental models and conducted crash tests using crash test dummies or human corpses have definitely shown the potential of seat belts as a basic safety device, reducing the risk of injury (Serre et al. 2007).

\section{Case presentation}

We report a case of death of a 57-year-old licensed driver who was involved in a car accident and impacted the roadside pillar frontally at a high speed. His anthropometric characteristics were as follows: height $-170 \mathrm{~cm}$, weight $-120 \mathrm{~kg}$, and the maximum girth $-135 \mathrm{~cm}$. During the crime scene investigation, it was found that the car was severely deformed due to the impact. The driver was found dead in the driver's seat with the seat belt on. The deformations of the car around the driver's seat were minimal. The steering wheel airbag was missing. The driver was very overweight with a pronounced midriff-the abdomen was greatly extended forward and sideways, disproportionate to the rest of the body. The type of the seat belt was a widespread 3-point (lap-shoulder) model. The lower horizontal part of the seat belt was passing over the iliac and pubic areas covered by a massive anterior abdominal wall. The shoulder part of the belt was lifted from the abdomen and covered the area high above the epigastrium. The external examination of the corpse showed two linear bruises, which were seen under the diagonal and transverse component of the 3-point belt. The upper bruise was located on the skin of the chest wall from the left collar bone to the right medial wall of the axillary fossa and the lower bruise, in the lower part of the anterior abdominal wall (Fig. 1).

The internal examination revealed well-defined suffusions in deep underlying soft tissues. No other contact injuries of the trunk were found. Adipose tissue of the anterior abdominal wall had a thickness of $7 \mathrm{~cm}$.

About $2500 \mathrm{ml}$ of blood were found in the peritoneal cavity. There was retroperitoneal hemorrhage. The abdominal aorta at level of first lumbar spine vertebra was torn in its rear wall (Fig. 2).

The anterior longitudinal ligament of the spine was torn. There was a full transverse fracture involving the body and pedicles of the 10th thoracic vertebra (Fig. 3). The posterior longitudinal ligament was intact. All soft tissues in close proximity were intensely suffused.

Other intra-abdominal injuries were not detected. The stomach was enlarged and filled with almost $2000 \mathrm{ml}$ food content.

\section{Discussion}

The study of road accidents shows that the use of seat belts affects the type and severity of injuries. The vast variety of typical injuries related to wearing a seat belt is united under the name "seat belt trauma". It includes

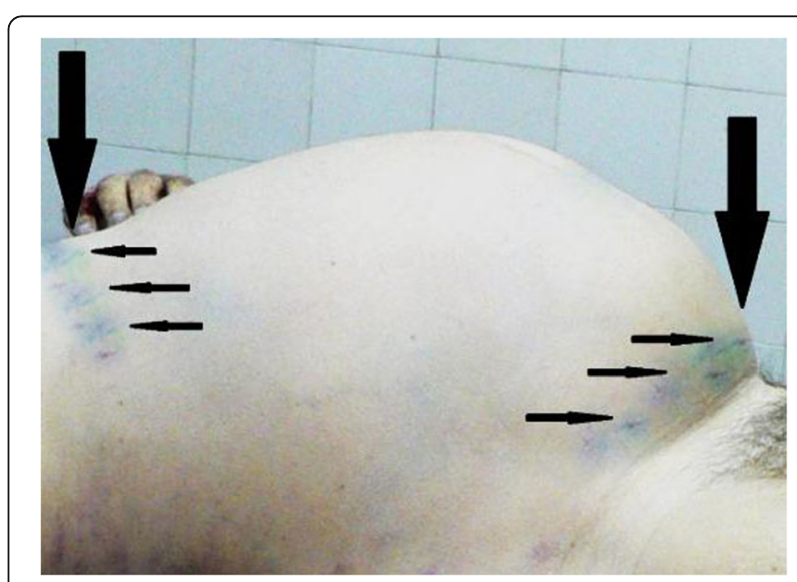

Fig. 1 The points where the seat belt was holding the body. The bruises from the seat belt are visible 


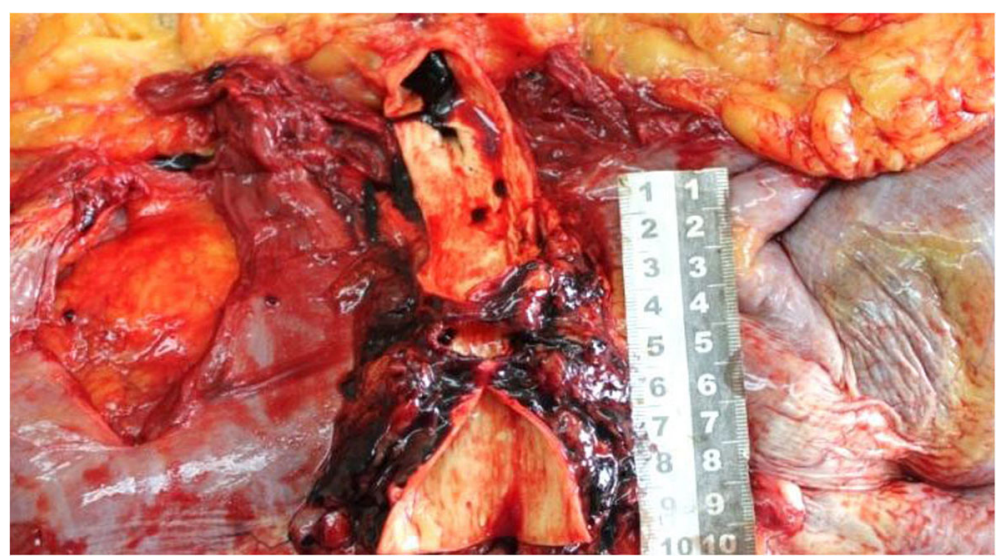

Fig. 2 Rupture of the aorta

soft tissue injuries, the locomotor system, and internal organs, arising from the process of "restraining" of the body by the belt (Chandler et al. 1997; Dehner 1971; Greingor and Lazarus 2006). Some of the very common disabilities are so called "whiplash" spinal cord injuries. They include different severity of damages in joint-ligament, bone structures, spinal cord, or cartilage intervertebral discs of the spine when the borders of normal physiological movements are crossed (Huelke et al. 1995; Huelke and Kaufer 1975). Due to the use of the most common 3-point seat belts of the "lap-shoulder" type, whiplash disabilities affect most often the cervical spine. In case of a sudden stop of the vehicle or a frontal impact, the head sharply continues its forward motion based on the physical law of conservation of energy. Depending on the value of the deceleration, the relative weight of the head can be increased many times. This causes hyperflexion (bending forward) in the cervical spine and leads to its disability (Saukko and Knight 2004; Ali and Giddins 2008).
The presented case is a very unusual variant of damage of spine and related to it anatomical structures under the influence of the transmission of forces applied to the body, as a result of a frontal collision at high speed when the driver of a car is restrained by a seat belt. The damage is in the thoracolumbar region of the spine. This location is most commonly obtained by the use of horizontal 2-point belts (lap-type), when a frontal impact causes a forceful hyperflexion. Rouhana et al. (2003) described that the 4-point belt in front impacts appeared to shift load to the clavicles and pelvis and to reduce traction of the shoulder belt across the chest, resulting in a reduction in chest deflection by a factor of two. This is associated with a 5- to 500-fold reduction in thoracic injury risk, including the thoracic part of the vertebral column. Based on their survey in four of six post mortem examinations, human subjects restrained by 4-point belts during $40 \mathrm{~km} / \mathrm{h}$ sled tests, chest compression was zero or negative, and the fractures were nearly eliminated. In general the effect of 4-point seat belt is

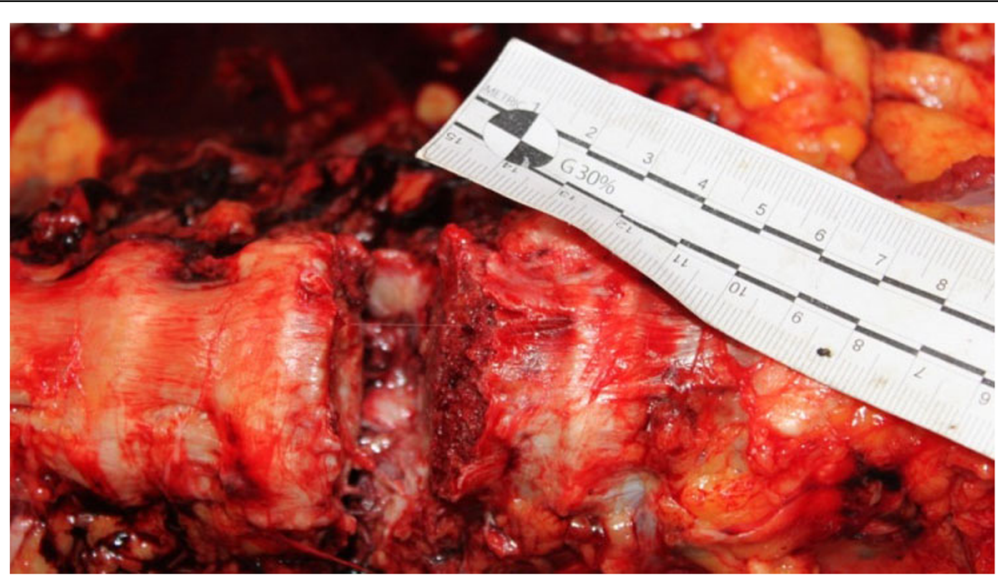

Fig. 3 The fracture of the vertebra 
associated with the ability to prevent submarining under the lap.

The cause of death was acute massive blood loss due to traumatic rupture of the abdominal aorta associated with a fracture of the 10th thoracic vertebra. The mechanism of the injury to the aorta relates to the biomechanical forces incurred on the abdominal aorta, which is tethered between the spinal column and the peritoneum and abdominal viscera. These forces disrupt the intima and, depending on the magnitude of force, can lead to aortic transection (Shalhub et al. 2012). Incorrectly adjusted straps allow the body to move forward and cause a violent hyperextension of the thoracolumbar spine (submarining). Thus, it is possible that the damage to the aorta may be caused by the ragged ends of the fractured spine tearing the aorta which is stretched over it. Simultaneous abdominal injuries and vertebral fractures were initially described in 1962 as a "seat belt syndrome". Dajee described the "seat belt aorta" as the injury to the aorta by a seat belt during a collision (Dajee et al. 1979).

The cause of the trauma may be identified by the comparison and analysis of all data obtained - the mechanism of the accident, age, sex, body mass index, anthropometric characteristics, and the type and location of injuries. The nature and severity of injuries and their consequences are varied and are determined in each specific situation of the technological parameters of the car, the speed of the terrain and road conditions, driving skills, anatomical characteristics of victims, and others (Reagan 1995). They built laboratory scale models or make computer dynamic simulators, which set a maximum number of manageable parameters-some constant, and other variables in order to simulate controlled, but most real situations that can be modeled, photographed, and studied in details (Yang et al. 2006). In our case, the trunk and especially abdominal region of the driver were extremely massive and heavy, with increased fat. The stomach was extended and filled with food. His age and the mass of the body determine the reduced resistance to dynamic loads and mostly in the spine according to the facts that there is a $10 \%$ loss of skeletal muscle mass by the age 50 years and the kinetic energy is dependent on the mass and velocity. In addition, the pressure of adjacent organs, which was transmitted to the abdominal wall, was also very high, proportionally to their weights.

The position of the seat belt sign was atypical, which showed the "submarining" of the body during the car accident. The lower part held the pelvis to the seat. The upper oblique part, raised high above the abdomen, held the upper part of the chest and shoulder girdle to the seat back. The bloated and heavy abdominal area was between them, free to move forward as submarining under the diagonal component of the 3-point strap. The concrete evidence of this motion was the presence of the fracture of the thoracic vertebra. Although the seat belt was placed, the driver was not actually restrained. Thus, the presence of atypical position of the seat belt sign and overweight were the predictors of severe blunt abdominal trauma. The presence of the "seat belt mark" sign should alert the physician to the high likelihood of specific internal injuries (Velmahos et al. 1999).

Some anthropometric characteristics of injured persons or incorrectly positioned straps can increase the danger of injury. Where the person is too small for the harness, such as a child or a small woman, the body may slide from under the strap (submarining)-or it may act as a garrote around the neck. Pregnant women also have problems with belts (Saukko and Knight 2004). They represent high-risk groups who are particularly vulnerable to injuries resulting from inappropriate seat belt application, and the opportunity for education on seat belt application should not be missed in all healthcare contacts (Masudi et al. 2017) because of their body disproportions, as in our case.

\section{Conclusions}

The analysis shows that the driver's body disproportion, combined with an inappropriate seat belt application, caused the damages and fatal outcome of the accident. It is incorrect to think that if perished the victim was not with seat belt on, he would survive. The safest seatbelt type for occupants with a similar figure would be the 4-point seat belt, which is used in children's car seats and in sports cars. This type of safety belt is crossed over the chest and abdomen, and better holds the entire trunk at dynamic loads in all directions.

Authors' contributions

All authors have equally participated in this work. All authors read and approved the final manuscript.

Ethics approval and consent to participate Not needed; this is a post mortem case report

Consent for publication

Not applicable.

Competing interests

The authors declare that they have no competing interests.

\section{Publisher's Note}

Springer Nature remains neutral with regard to jurisdictional claims in published maps and institutional affiliations.

\section{Author details}

${ }^{1}$ Department of Forensic Medicine and Deontology, Medical

University-Plovdiv, Bulgaria, 15a Vassil Aprilov Blv., 4000 Plovdiv, Bulgaria.

${ }^{2}$ Department of Forensic Medicine and Deontology, Medical

University-Sofia, Bulgaria, 2 Zdrave Str., 1431 Sofia, Bulgaria. ${ }^{3}$ Department of Anatomy, Histology and Embryology, Medical University-Plovdiv, Bulgaria, 15a Vassil Aprilov Blv., 4000 Plovdiv, Bulgaria. 
Received: 19 January 2018 Accepted: 22 August 2018

Published online: 03 September 2018

\section{References}

Ali A, Giddins G (2008) Subacromial impingement in patients with whiplash injury to the cervical spine. J Orthop Surg Res 3:25

Bertrand S, Cuny S, Petit P et al (2008) Traumatic rupture of thoracic aorta in real-world motor vehicle crashes. Traffic Inj Prev 9:153-161

Brundage SI, Harruff R, Jurkovich GJ et al (1998) The epidemiology of thoracic aortic injuries in pedestrians. J Trauma 45:1010-1014

Burkhart HM, Gomez GA, Jacobson LE et al (2001) Fatal blunt aortic injuries: a review of 242 autopsy cases. J Trauma 50:113-115

Chandler C, Lane J, Waxman K (1997) Seatbelt sign following blunt trauma is associated with increased incidence of abdominal injury. Am Surg 63(10): 885-888

Dajee H, Richardson IW, lype MO (1979) Seat belt aorta: acute dissection and thrombosis of the abdominal aorta. Surgery 85(3):263-267

Dehner J (1971) Seatbelt injuries of the spine and abdomen. Am J Roentgenol 111:833-843

Fitzharris M, Franklyn M, Frampton R et al (2004) Thoracic aortic injury in motor vehicle crashes: the effect of impact direction, side of body struck, and seat belt use. J Trauma 57:582-590

Freni L, Barbetta I, Mazzaccaro D, Settembrini AM, Dallatana R, Tassinari L, Settembrini PG (2013) Seat belt injuries of the abdominal aorta in adults-case report and literature review. Vasc Endovasc Surg 47(2):138-147

Frey CF (1970) Trauma to internal organs. Human anatomy, impact, injuries and human tolerances. Society of Automotive Engineers, Warrendale SAE 700195

Gotzen L, Flory PJ, Otte D (1980) Biomechanics of aortic rupture at classical location in traffic accidents. Thorac Cardiov Surg 28:64-68

Greendyke RM (1966) Traumatic rupture of the aorta: special reference to automobile accidents. JAMA 195:527-530

Greingor J, Lazarus S (2006) Chest and abdominal injuries caused by seat belt wearing. South Med J 99(4):534-535

Hossack DW (1974) Death at the wheel. A consideration of cardiovascular disease as a contributory factor to road accidents. Med J Aust 1:164-166

Huelke D, Kaufer H (1975) Vertebral column injuries and seat belts. J Trauma 15(4):304-318

Huelke D, Mackay G, Morris A (1995) Vertebral column injuries and lap-shoulder belts. J Trauma 38(4):547-556

Ichikawa M, Nakahara S, Wakai S (2002) Mortality of front-seat occupants attributable to unbelted rear-seat passengers in car crashes. Lancet 359(9300):43-44

Katyal D, McLellan BA, Brenneman FD et al (1997) Lateral impact motor vehicle collisions: significant cause of blunt traumatic rupture of the thoracic aorta. J Trauma 42:769-772

Masudi T, McMahon H, Scott J, Lockey A (2017) Seat belt-related injuries: a surgical perspective. JETS 10:70-73

McEwen L, Woodruff P, Archibild C (1999) Lap belt abdominal aortic trauma. Australas Radiol 43:369-371

Michaels AJ, Gerndt SJ, Taheri PA et al (1996) Blunt force injury of the abdominal aorta. J Trauma 41:105-109

Nagy K, Fabian T et al (2000) Guidelines for the diagnosis and management of blunt aortic injury: an EAST Practice Management Guidelines Work Group. J Trauma 48(6):1128-1143

Newman RJ, Rastogi S (1984) Rupture of the thoracic aorta and its relationship to road traffic accident characteristics. Injury 15:296-299

Primm RK, Karp RB, Schrank JP (1979) Multiple cardiovascular injuries and motor vehicle accidents. JAMA 241:2540-2541

Reagan J (1995) Vehicle compatibility with roadside safety hardware. Public Roads 59(2)

Richens D, Kotidis K, Neale M et al (2003) Rupture of the aorta following road traffic accidents in the United Kingdom 1992-1999. The results of the co-operative crash injury study. Eur J Cardio-thorac 23:143-148

Rouhana SW, Bedewi PG, Kankanala SV, Prasad P, Zwolinski JJ, Meduvsky AG, Rupp JD, Jeffreys TA, Schneider LW (2003) Biomechanics of 4-point seat belt systems in frontal impacts. Stapp Car Crash J 47:367-399

Sampsell JW (1967) Rupture of the gastroduodenal artery. JAMA 202(9):914-915

Saukko P, Knight B (2004) Knights forensic pathology (third edition). Edward Arnold (Publishers) Ltd, London.

Schulman Cl, Carvajal D, Lopez PP et al (2007) Incidence and crash mechanisms of aortic injury during the past decade. J Trauma 62:664-667
Serre T, Masson C, Perrin C et al (2007) Real accidents involving vulnerable road users: in-depth investigation, numerical simulation and experimental reconstitution with PMHS. Int J Crashworthiness 12(3):227-234

Sevitt S (1977a) The mechanisms of traumatic rupture of the thoracic aorta. Br J Surg 64:166-173

Sevitt S (1977b) Traumatic ruptures of the aorta: a clinico-pathological study. Injury 8:159-173

Shalhub S, Starnes B, Tran N et al (2012) Blunt abdominal aortic injury. J Vasc Surg 55:1277-1286

Sutorius DJ, Schreiber JT, Helmsworth JA (1973) Traumatic disruption of the thoracic aorta. J Trauma 13:583-590

Velmahos GC, Tatevossian R, Demetriades D (1999) The "seat belt mark" sign: a call for increased vigilance among physicians treating victims of motor vehicle accidents. Am Surg 65(2):181-185

Viano DC (2011) Chest impact experiments aimed at producing aortic rupture. Clin Anat 24:339-349

Wilson SK, Hutchins GM (1982) Aortic dissecting aneurysms: causative factors in 204 subjects. Arch Pathol Lab Med 106:175-180

Yang K, Hu J, White N et al (2006) Development of numerical models for injury biomechanics research: a review of 50 years of publications in the Stapp Car Crash Conference. Stapp Car Crash J 50:429-490

\section{Submit your manuscript to a SpringerOpen ${ }^{\odot}$ journal and benefit from:}

- Convenient online submission

- Rigorous peer review

- Open access: articles freely available online

High visibility within the field

- Retaining the copyright to your article

Submit your next manuscript at $>$ springeropen.com 